\title{
Aortic Body
}

National Cancer Institute

\section{Source}

National Cancer Institute. Aortic Body. NCI Thesaurus. Code C97112.

A small mass that is located in the inferior surface of the aortic arch. It functions as a peripheral chemoreceptor and is composed of glomus cells. 